\title{
Determination of trace element incorporation into tests of in vitro grown foraminifera by micro- SYXRF - a basis for the development of paleoproxies
}

\author{
U. Kramar (1), D. Munsel (1), Z. Berner (1), J. Bijma (2), and G. Nehrke (2) \\ (1) Universität Karlsruhe, Mineralogy and Geochemistry, Karlsruhe, Germany (utz.kramar@img.uka.de), (2) Biogeosciences, \\ Alfred Wegener Institute for Polar and Marine Research, Bremerhaven, Germany
}

Trace element chemistry and isotopic composition of calcareous foraminiferal tests reflect the environment in which they grow. Consequently, geochemical parameters of the tests are often used as paleo-proxies to constrain the environmental conditions in ancient seas (e.g. Boyle, 1981).

Currently only a limited number of trace elements is used as proxies. Difficulties arise from the fact that often a proxy depends on several parameters and that seawater-chemistry may be influenced by local sources such as hydrothermalism or by changes in redox conditions. Reliable experimental data on elements which can be considered as diagnostic for hydrothermal activity and/or changing redox conditions are non-existent to scarce.

We have cultured shallow benthic foraminifera (Ammonia tepida) under controlled conditions at defined trace element levels $(5,10,20$-fold average seawater concentration) representing two distinct environmental simulations, one for hydrothermal ( $\mathrm{Mn}, \mathrm{Cu}, \mathrm{Co}, \mathrm{Ni}$ ) and another for changing redox conditions ( $\mathrm{Mo}, \mathrm{As}, \mathrm{Cr}$, and $\mathrm{V}$ ). The goal of our investigations is to provide diagenetically unbiased experimental trace element data in foraminiferal shells as a basis for a more complete understanding of trace element partition between seawater and foraminifera shell calcite as a function of environmental conditions.

The foraminifers did not reproduce in culture but grew new chambers as evidenced by labelling with calcein (Bernhard et al., 2004). The trace element uptake into old (field grown) and new chambers was subsequently analysed.

Using excitation energies of $12.5 \mathrm{keV}$ and focusing by refractive lenses to a spot size of $2 \times 5 \mu \mathrm{m}$ at FLUO-beamline of ANKA and $25 \mathrm{keV}$ and confocal poly capillary optics at HASYLAB Beamline L, old chambers and new ones of the same foraminifera have been analyzed separately for $\mathrm{Ni}, \mathrm{Cu}, \mathrm{Zn}, \mathrm{Mn}, \mathrm{As}, \mathrm{Cr}, \mathrm{V}, \mathrm{Sr}$ and Mo. The data will be compared with results from LA-ICP/MS analytics. Concentrations of the elements of interest in the newly grown chambers are varying in the $0 . \mathrm{x}$ to $1 \mathrm{xx} \mu \mathrm{g} / \mathrm{g}$ range. Because of these low concentrations long measuring times $(\sim 500 \mathrm{~s})$ were necessary at each spot. The trace element contents in the foraminiferal test were quantified by fundamental parameters. Path length of the incoming beam was determined from the ratio of the primary and secondary monitor. Since the foraminifera shells consist of nearly pure calcite, Ca was used as internal standard to calculate the average path length of the outgoing beam.

Arsenic, $\mathrm{V}$ and $\mathrm{Ni}$ concentrations in the test correlate with their concentration in seawater. Nevertheless considerable variations, possibly reflecting vital effects, are observed between newly grown chambers of individuals grown under identical culture conditions.

Boyle, E.A. (1981): Cadmium, zinc, copper, and barium in foraminifera tests. Earth and Planetary Science letters 53: $11-35$.

Bernhard, J.M., Blanks, J.K. Hintz, C.J. \& Chandler, G.T. (2004): Use of the fluorescent calcite marker calcein to label foraminiferal tests. Journal of Foraminiferal Research 34: 96-101. 